Background: Experts emphasize early diagnosis and treatment in RA, but the widely used diagnostic criterias fail to meet the accurate judgment of early rheumatoid arthritis. In 2012, Professor Zhanguo Li took the lead in establishing ERA "Chinese standard", and its sensitivity and accuracy have been recognized by peers. However, the optimal first-line treatment of patients (pts) with undifferentiated arthritis (UA), early rheumatoid arthritis (ERA), and rheumatoid arthritis (RA) are yet to be established.

Objectives: To evaluate the efficacy and safety of Iguratimod-based (IGU-based) Strategy in the above three types of pts, and to explore the characteristics of the effects of IGU monotherapy and combined treatment.

Methods: This prospective cohort study (ClinicalTrials.gov Identifier NCT01548001) was conducted in China. In this phase 4 study pts with RA (ACR 1987 criteria[1]), ERA (not match ACR 1987 criteria[1] but match ACR/ EULAR 2010 criteria[2] or 2014 ERA criteria[3]), UA (not match classification criteria for ERA and RA but imaging suggests synovitis) were recruited. We applied different treatments according to the patient's disease activity at baseline, including IGU monotherapy and combination therapies with methotrexate, hydroxychloroquine, and prednisone. Specifically, pts with LDA and fewer poor prognostic factors were entered the IGU monotherapy group ( $25 \mathrm{mg}$ bid), and pts with high disease activity were assigned to combination groups. A Chi-square test was applied for comparison. The primary outcomes were the proportion of pts in remission (REM)or low disease activity (LDA) that is DAS28-ESR $<2.6$ or 3.2 at 24 weeks, as well as the proportion of pts, achieved ACR20, Boolean remission, and good or moderate EULAR response $(\mathrm{G}+\mathrm{M})$.

Results: A total of 313 pts (26 pts with UA, 59 pts with ERA, and 228 pts with RA) were included in this study. Of these, $227 / 313(72.5 \%)$ pts completed the 24-week follow-up. The results showed that $115 / 227(50.7 \%)$, $174 / 227$ (76.7\%), 77/227 (33.9\%), 179/227 (78.9\%) pts achieved DAS28ESR defined REM and LDA, ACR20, Boolean remission, G+M response, respectively. All parameters continued to decrease in all pts after treatment (Fig 1).

Compared with baseline, the three highest decline indexes of disease activity at week 24 were SW28, CDAI, and T28, with an average decline rate of $73.8 \%, 61.4 \%, 58.7 \%$, respectively. Results were similar in three cohorts.

We performed a stratified analysis of which IGU treatment should be used in different cohorts. The study found that the proportion of pts with UA and ERA who used IGU monotherapy were significantly higher than those in the RA cohort. While the proportion of triple and quadruple combined use of IGU in RA pts was significantly higher than that of ERA and UA at baseline and whole-course (Fig 2).

A total of $81 / 313(25.8 \%)$ pts in this study had adverse events (AE) with no serious adverse events. The main adverse events were infection(25/313, $7.99 \%)$, gastrointestinal disorders(13/313,4.15\%), liver dysfunction(12/313,3.83\%) which were lower than $259 / 2666(9.71 \%)$ in the previous Japanese phase IV study[4].

The most common reasons of lost follow-up were: 1) discontinued after remission $25 / 86(29.1 \%)$; 2) lost 22/86 (25.6\%); 3) drug ineffective 19/86 (22.1\%).
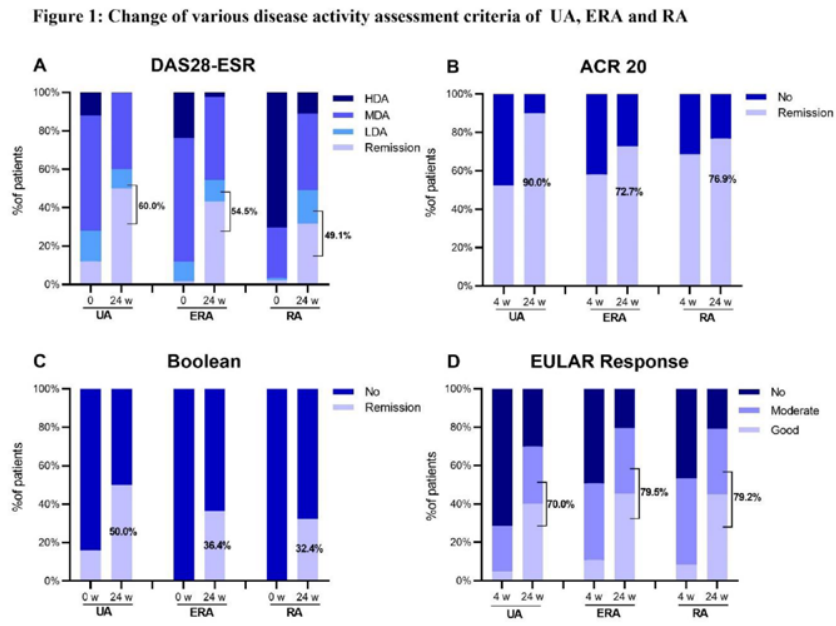

(A) DAS28-ESR disease activity of patients at baseline and week 24(Remission, DAS28-ESR $\leqslant 2.6$; Low disease activity (LDA) $2.6<$ DAS28-ESR $\leqslant 3.2 ;$ Moderate disease activity (MDA), $3.2<$ DAS28-ESR $\leqslant 5.1$; and High disease activity (HDA), DAS28 DAS28-Disease Activity Score 28 joints: ESR-erythrocyte sedimentation rate; EUT

$\mathrm{ACR}=$ American College of Rheumatology.

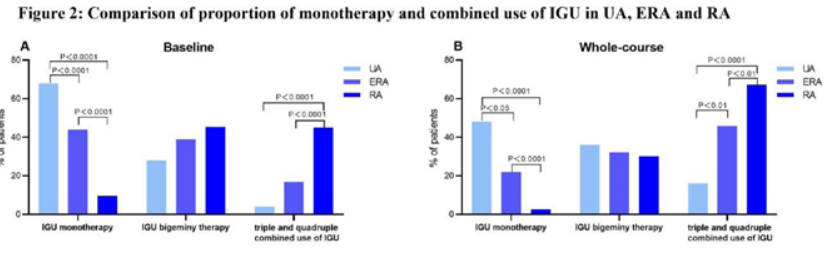

Conclusion: Both IGU-based monotherapy and combined therapies are tolerant and effective for treating UA, ERA, and RA, while the decline in joint symptoms was most significant. Overall, IGU combination treatments were most used in RA pts, while monotherapy was predominant in ERA and UA pts.

REFERENCES:

[1] Levin RW, et al. Scand J Rheumatol 1996, 25(5):277-281.

[2] Kay J, et al. Rheumatology 2012, 51(Suppl 6):vi5-9.

[3] Zhao J, et al. Clin Exp Rheumatol 2014, 32(5):667-673.

[4] Mimori T, et al. Mod Rheumatol 2019, 29(2):314-323.

Disclosure of Interests: None declared

DOI: 10.1136/annrheumdis-2021-eular.91

\section{POS0648 1 SURVIVAL ANALYSIS OF TIME TO FIRST ADVERSE DRUG REACTION AND DRUG SURVIVAL IN RHEUMATOID ARTHRITIS PATIENTS TREATED WITH METHOTREXATE AND HYDROXYCHLOROQUINE MONOTHERAPIES OR COMBINATION THERAPY}

K. Velthuis ${ }^{1}$, M. Nguyen ${ }^{1}$, J. Scholl ${ }^{1}$, J. Jansen ${ }^{1}$, J. Van Lint ${ }^{1}$, P. Ten Klooster ${ }^{2,3}$ H. Vonkeman ${ }^{3,4}$, N. Jessurun ${ }^{1}{ }^{1}$ Netherlands Pharmacovigilance Centre Lareb, Research Department, 's-Hertogenbosch, Netherlands; ${ }^{2}$ Transparency in Healthcare B.V., Hengelo, Netherlands; ${ }^{3}$ University of Twente, Department of Psychology, Health \& Technology, Enschede, Netherlands; ${ }^{4}$ Medisch Spectrum Twente, Department of Rheumatology and Clinical Immunology, Enschede, Netherlands

Background: Methotrexate (MTX) and hydroxychloroquine (HCQ) are first line treatments of rheumatoid arthritis (RA). Adverse drug reactions (ADRs) during treatment with these drugs are common. Survival analysis on time to first ADR and on first time drug use duration have not yet been performed for these drugs in real-world settings.

Objectives: To compare proportions of patients with ADRs during first time use of either MTX monotherapy, $\mathrm{HCQ}$ monotherapy or MTX+HCQ combination therapy and to compare survival to first ADR and drug survival between these drugs.

Methods: Retrospective single centre cohort study including adult RA patients treated with either MTX monotherapy, HCQ monotherapy or MTX+HCQ combination therapy. First time users between 1 January 2003 and 30 April 2020 were followed until discontinuation of their first time drug use. The proportion of patients with ADRs was defined as the percentage of patients experiencing an ADR during their first time drug use. Survival to first ADR and drug survival of first time drug use were also assessed. MTX $+\mathrm{HCQ}$ use was considered combination therapy when the start dates of these drugs differed less than 14 days. For both monotherapies, end of first time drug use was defined as drug discontinuation for more than 90 days. For $\mathrm{MTX}+\mathrm{HCQ}$ combination therapy, end of first time drug use was defined as discontinuation of either MTX, HCQ or both for more than 90 days. Differences in the proportion of patients experiencing an ADR during first time drug use of $M T X, H C Q$ or a combination of both was statistically tested using Fisher's Exact Test. Survival to first ADR and drug survival were studied by Kaplan-Meier analysis and statistically tested by performing Log Rank tests.

Results: In total, 794 patients were included (MTX 363, HCQ 77, MTX+HCQ 354). For 156 patients (19.6\%) at least one ADR was registered during first time drug use (MTX 59 [16.3\%], HCQ 9 [11.7\%], MTX+HCQ 88 [24.9\%]). Proportions of ADRs differed significantly between MTX monotherapy and $\mathrm{MTX}+\mathrm{HCQ}$ combination therapy $(p=0.005)$ and between $\mathrm{HCQ}$ monotherapy and $\mathrm{MTX}+\mathrm{HCQ}$ combination therapy $(p=0.011)$. Survival to first ADR also differed significantly for both monotherapies compared to $\mathrm{MTX}+\mathrm{HCQ}$ combination therapy (medians not reached, $p<0.001$ and $p<0.008$, respectively (figure 1A)). Drug survival differed significantly between MTX and HCQ monotherapy and between MTX monotherapy and MTX $+\mathrm{HCQ}$ combination therapy (median survival MTX 3.32 years $(95 \% \mathrm{Cl}$ [2.81-3.83]; $\mathrm{HCQ} 1.39$ years (95\% Cl [1.03-1.75]); MTX+HCQ 1.23 years (95\% Cl [1.11-1.34]), both $p<0.001$ (figure 1B)). 


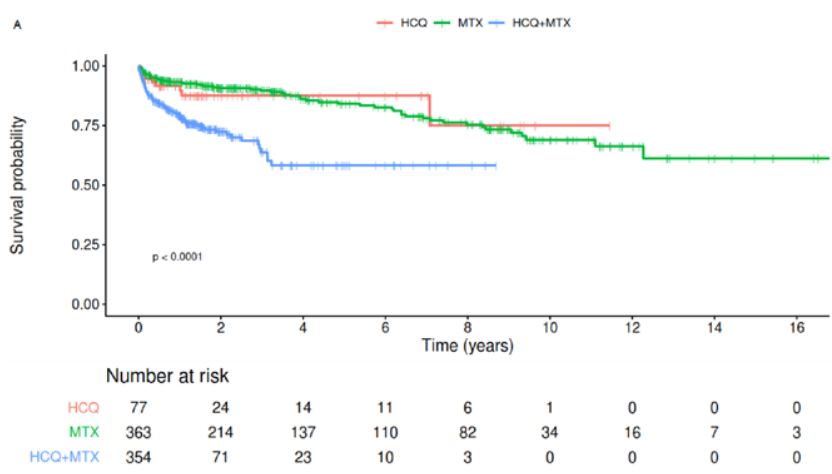

B

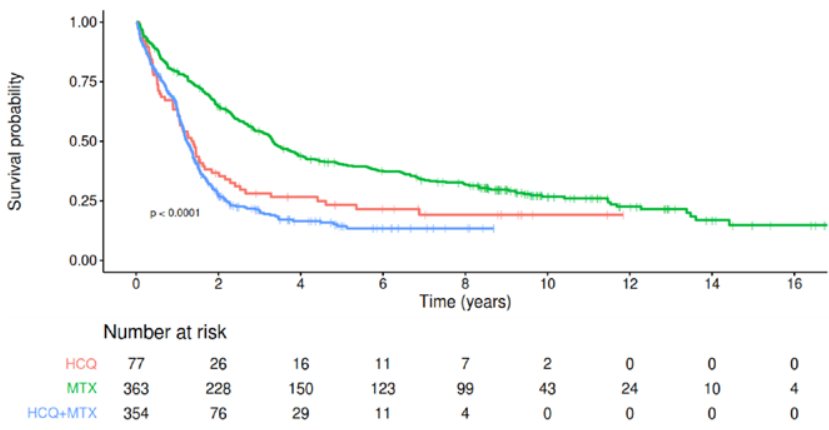

Figure 1. Kaplan-Meier curves of MTX and HCQ monotherapies and MTX+HCQ combination therapy, with (a) survival to first ADR and (b) drug survival.

Conclusion: Patients using $\mathrm{MTX}+\mathrm{HCQ}$ combination therapy are more likely to experience an ADR during the first time drug use compared to MTX and $\mathrm{HCQ}$ monotherapies. MTX+HCQ combination therapy also leads to experiencing an ADR sooner compared to both monotherapies. Drug survival of patients treated with $\mathrm{HCQ}$ monotherapy as well as $\mathrm{MTX}+\mathrm{HCQ}$ combination therapy is shorter compared to MTX monotherapy.

Disclosure of Interests: Kimberly Velthuis: None declared, My Nguyen: None declared, Joep Scholl: None declared, Jurriaan Jansen: None declared, Jette van Lint: None declared, Peter ten Klooster: None declared, Harald Vonkeman Consultant of: BMS, Celgene, Celltrion, Galapagos, Gilead, Janssen-Cilag, Lilly, Novartis, Pfizer, Sanofi-Genzyme, Grant/research support from: Abbvie, Naomi Jessurun: None declared

DOI: 10.1136/annrheumdis-2021-eular.181

\section{POS0649 BARICITINIB PROVIDES GREATER IMPROVEMENTS IN PATIENT-REPORTED OUTCOMES ACROSS ALL DISEASE ACTIVITY LEVELS COMPARED TO PLACEBO AND ADALIMUMAB IN RHEUMATOID ARTHRITIS}

P. C. Taylor ${ }^{1}$, R. Blanco ${ }^{2}$, K. Ikeda ${ }^{3}$, B. Jia ${ }^{4}$, Y. F. Chen ${ }^{4}$, C. Walls ${ }^{4}$, E. Haladyj ${ }^{4}$, B. Fautrel ${ }^{5} .{ }^{1}$ University of Oxford, Botnar Research Centre, Nuffield Department of Orthopaedics, Rheumatology and Musculoskeletal Sciences, Oxford, United Kingdom; ${ }^{2}$ Hospital Universitario Marqués de Valdecilla, Department of Rheumatology, Santander, Spain; ${ }^{3}$ Chiba University Hospital, Department of Allergy and Clinical Immunology, Chiba, Japan; ${ }^{4}$ Eli Lilly and Company, Lilly Research Laboratories, Indianapolis, United States of America; ${ }^{5}$ Sorbonne University - Assistance Publique Hôpitaux de Paris, Pitie Salpetriere Hospital, Rheumatology Department, Paris, France

Background: Baricitinib (BARI) is a JAK1/JAK2 inhibitor which provides improvements to clinical signs, symptoms, and patient-reported outcomes (PROs) in patients with rheumatoid arthritis $[1,2]$

Objectives: The effect of BARI on the relationship between disease activity and pain has been explored previously [3]. The purpose of this post hoc analysis was to determine the association between additional PROs (physical function, fatigue, and duration of morning joint stiffness) and disease activity status after 12 weeks of treatment and to evaluate whether patients with an inadequate response to methotrexate treated with BARI $4 \mathrm{mg}$ experienced greater PRO improvement than patients treated with either placebo (PBO) or adalimumab (ADA) across all levels of disease activity.

Methods: Data for these analyses were derived from the Phase 3 study RA-BEAM ( $\mathrm{N}=1305$; NCT01710358). Pain was evaluated using a $0-100 \mathrm{~mm}$ visual analog scale, physical function was assessed using the Health Assessment Questionnaire-Disability Index (HAQ-DI), fatigue was measured using the Functional Assessment of Chronic Illness Therapy-Fatigue (FACIT-F) scale, and duration of morning joint stiffness (MJS, minutes) was reported by the patient. Disease activity was measured using the Clinical Disease Activity Index (CDAl) and categorized as remission (REM, $\leq 2.8$ ), low disease activity (LDA, >2.8 to $\leq 10$ ), moderate disease activity (MDA, $>10$ to $\leq 22$ ), or high disease activity (HDA, >22). Linear regression was used to model the relationship between change in PROs at Week 12 (response) and CDAl values at Week 12 (primary explanatory variable) to evaluate the extent of improvement in PROs with BARI relative to $\mathrm{PBO}$ and $A D A$ across a spectrum of disease activity levels. Last observation carried forward was used to impute missing values.

Results: At baseline, $91 \%$ of patients were classified as having HDA and $9 \%$ as having MDA by CDAI across all treatment groups. After 12 weeks of treatment, $2 \%, 7 \%$, and $9 \%$ of patients achieved REM; $16 \%, 27 \%$, and $33 \%$ of patients achieved LDA; and $33 \%, 40 \%$, and $38 \%$ of patients achieved MDA with PBO, ADA, and BARI, respectively [3].

At Week 12, the estimated changes in measures of pain and physical function, as well as duration of MJS, for BARI $4 \mathrm{mg}$ were greater than both PBO and ADA at all disease activity level threshold values of CDAI (Table 1). The estimated change in fatigue for BARI $4 \mathrm{mg}$ was similar to that of ADA, and greater than PBO, at all disease activity level threshold values (Table 1).

Table 1. Estimate of PRO Improvement by Disease Activity Threshold Level (CDAI) at Week 12

\begin{tabular}{|c|c|c|c|c|c|c|c|c|c|}
\hline \multirow[t]{2}{*}{ PRO } & \multicolumn{3}{|c|}{$\mathrm{CDAl}=2.8$} & \multicolumn{3}{|c|}{$\mathrm{CDAl}=10$} & \multicolumn{3}{|c|}{$\mathrm{CDAl}=22$} \\
\hline & PBO & ADA & $\begin{array}{l}\text { BARI } \\
4 \mathrm{mg}\end{array}$ & PBO & ADA & BARI $4 \mathrm{mg}$ & РBO & ADA & BARI $4 \mathrm{mg}$ \\
\hline Pain VAS ${ }^{a}(\mathrm{~mm})$ & -28.4 & -37.9 & -40.9 & -24.5 & -32.6 & -36.1 & -18.0 & -23.7 & -28.1 \\
\hline$H A Q-D I^{b}$ & -0.6 & -0.7 & -0.9 & -0.5 & -0.7 & -0.7 & -0.4 & -0.5 & -0.6 \\
\hline FACIT-F ${ }^{c}$ & 9.8 & 11.8 & 11.1 & 8.8 & 10.6 & 10.2 & 7.0 & 8.7 & 8.7 \\
\hline Duration of MJS ( $\mathrm{min})$ & -6.9 & -37.8 & -64.9 & -6.3 & -35.3 & -55.7 & -5.3 & -31.3 & -40.2 \\
\hline
\end{tabular}

${ }^{\text {aPain } V A S ~ s c o r e s ~ r a n g e ~ f r o m ~} 0$ (no pain) to 100 (worst pain).

bHAQ-DI scores range from 0 (no disability) to 3 (completely disabled).

${ }^{\mathrm{C}} \mathrm{FACIT-F}$ scores range from 0 (worst fatigue) to 52 (no fatigue)

Abbreviations: ADA, adalimumab; BARI, baricitinib; CDAI, Clinical Disease Activity Index FACIT-F, Functional Assessment of Chronic Illness Therapy-Fatigue; HAQ-DI, Health Assessment Questionnaire-Disability Index; MJS, morning joint stiffness; PBO, placebo; PRO, patient-reported outcomes; VAS, visual analog scale.

Conclusion: Estimates of treatment differences suggest that patients treated with BARI 4 mg may experience greater improvements in pain, physical function and MJS duration than patients treated with PBO or ADA regardless of their disease activity status reached after 12 weeks of treatment. Using this approach improvements in fatigue with BARI $4 \mathrm{mg}$ may be greater than with $\mathrm{PBO}$ and similar to ADA after 12 weeks.

\section{REFERENCES:}

[1] Taylor, P.C., et al., N Engl J Med, 2017. 376(7): p. 652-662.

[2] Keystone, E.C., et al., Ann Rheum Dis, 2017. 76(11): p. 1853-1861.

[3] Taylor, P., et al., Arthritis Rheumatol, 2019. 71(S10): p. 2455-2457.

Acknowledgements: The authors would like to acknowledge Catherine Lynch with Eli Lilly and Company, for medical writing and project management support. Disclosure of Interests: Peter C. Taylor Consultant of: AbbVie, Biogen, Galapagos, Gilead, GlaxoSmithKline, Janssen, Eli Lilly, BMS, Pfizer, Roche, Celltrion, Sanofi, Nordic Pharma, Fresenius and UCB, Grant/research support from: Celgene, Galapagos, Gilead, Eli Lilly, Ricardo Blanco Speakers bureau: Abbvie, Pfizer, Roche, BMS, Janssen, Eli Lilly and MSD, Consultant of: Abbvie, Pfizer, Roche, BMS, Janssen, Eli Lilly and MSD, Grant/research support from: Abbvie, MSD, and Roche, Kei Ikeda Speakers bureau: Eli Lilly, Abbvie, Mitsubishi-Tanabe, Novartis, Paid instructor for: Abbvie, Grant/research support from: Mitsubishi-Tanabe, Bochao Jia Shareholder of: Eli Lilly and Company, Employee of: Eli Lilly and Company, Yun-Fei Chen Shareholder of: Eli Lilly and Company, Employee of: Eli Lilly and Company, Chad Walls Shareholder of: Eli Lilly and Company, Employee of: Eli Lilly and Company, Ewa Haladyj Employee of: Eli Lilly and Company, Bruno Fautrel Speakers bureau: Eli Lilly, Consultant of: AbbVie, Biogen, Bristol-Myers Squibb, Celgene, Janssen Pharmaceuticals, Eli Lilly and Company, Medac, MSD, NORDIC Pharma, Novartis, Pfizer Inc., Roche, SanofiAventis, SOBI, UCB, Grant/research support from: AbbVie, Eli Lilly and Company, MSD, Pfizer Inc

DOI: 10.1136/annrheumdis-2021-eular.182

\section{POS0650 PREDICTORS OF DURABLE CLINICAL RESPONSE TO TOFACITINIB 11 MG ONCE DAILY WITH OR WITHOUT METHOTREXATE IN PATIENTS WITH RHEUMATOID ARTHRITIS: POST HOC ANALYSIS OF DATA FROM A PHASE 3B/4 METHOTREXATE WITHDRAWAL STUDY}

K. Yamaoka ${ }^{1}$, S. B. Cohen ${ }^{2}$, N. Sugiyama ${ }^{3}$, H. Shi ${ }^{4}$, J. L. Rivas ${ }^{5}$, A. Diehl ${ }^{4}$, J. S. Smolen ${ }^{6} .{ }^{1}$ Kitasato University, Department of Rheumatology and Infectious Diseases, Sagamihara, Japan; ${ }^{2}$ Metroplex Clinical Research Center, Dallas, 